O eixo e a roda, Belo Horizonte, v. 26, n. 1, p. 187-205, 2017

\title{
História \& teatro, teatro \& história: uma relação tão delicada ${ }^{1}$
}

\section{History \& theater, theater \& history: a delicate relationship}

Kátia Rodrigues Paranhos

Universidade Federal de Uberlândia, Uberlândia, Minas Gerais / Brasil akparanhos@uol.com.br

Resumo: Para o crítico inglês Eric Bentley, o teatro político se refere tanto ao texto teatral como a quando, onde e como ele é representado. Por vezes condenada como escapista, outras vezes incensada como ferramenta de libertação revolucionária, a arte, de modo geral, continua sendo um tema candente tanto na academia como fora dela. Não é à toa que Sérgio de Carvalho, diretor da Companhia do Latão, criada em 1997, e professor do curso de Artes Cênicas da Universidade de São Paulo, levanta uma questão fundamental: "Qual a função da arte dentro do aparelho cultural capitalista?". Este artigo aborda o tema do engajamento, de modo geral, levando em consideração a relação entre história e teatro, teatro e história, assim como os discursos produzidos sobre os seus processos coletivos de criação e de pesquisa teórica.

Palavras-chave: história e teatro; engajamento; teatro político.

Abstract: For the English critic Eric Bentley, political theater is both the theatrical text and when, where, and how it is staged. Sometimes condemned as escapist, others praised as a tool for revolutionary liberation, art generally remains a controversial topic within academia and

\footnotetext{
${ }^{1}$ Este texto baseia-se em uma conferência proferida no Programa de Pós-Graduação em Artes Cênicas da Universidade Federal de Ouro Preto (UFOP), em julho de 2015, juntamente ao Festival de Inverno de Ouro Preto e Mariana/Fórum das Artes 2015 e na mesa-redonda intitulada "História indisciplinada", ocorrida no XXIII Encontro Estadual da Anpuh-SP, na Unesp/Assis-SP, em setembro de 2016.
} 
elsewhere. It is no wonder that Sérgio de Carvalho, director of Companhia do Latão, created in 1997, and Drama and Theater professor at University of São Paulo, raises a crucial question: "What role does art play in the capitalist cultural apparatus?". This article addresses engagement in general taking into account the relationship between history and theater, theater and history, as well as the discourses on their collective creation and theoretical research processes.

Keywords:history and theater; engagement; political theater.

Recebido em 25 de fevereiro de 2017.

Aprovado em 26 de abril de 2017.

Arte é algo que se situa na estreita margem entre o real e o irreal [...]

é irreal e, no entanto, não é irreal; é real e, no entanto, não é real.

Chikamatsu Monzaemon (1653-1724)

\title{
1 Textos, sons e imagens
}

No início da década de 1990, na França, Jacqueline de Jomaron, ao destacar a especificidade da história do teatro, afirma:

\begin{abstract}
A história do teatro não pode ser escrita da mesma forma que as outras artes. Aquilo que é específico e essencial num espetáculo só continua vivo no espírito de seus contemporâneos. $\mathrm{O}$ teatro só existe no momento em que ele tem lugar e sua característica efêmera [...] ligada à sua própria natureza (JOMARON, 1992, p. 11, tradução minha).
\end{abstract}

A lógica, perceptível ao longo dos vários períodos da humanidade, é que a capacidade de apreender e de compreender a história e, portanto, de fazê-la está vinculada ao espírito do tempo de cada uma das diferentes épocas. Arte memorial na sua essência, que se eterniza unicamente nas lembranças do espectador, o teatro tem a tendência de envolver todas as artes, sendo algumas vezes tributário dessas outras manifestações. Sobre esse aspecto a historiadora francesa afirma que 
O teatro teve e tem cada vez mais a ambição de reunir todas as artes numa única: poesia e literatura, música e pintura, escultura e arquitetura. Ele possui, além disso, seus próprios meios de expressão: dicção, interpretação, dança, mímica, indumentária, iluminação. Enfim, os documentos que demarcam sua história na França, depoimentos, críticas, documentos administrativos, iconografia - incluindo-se aí a fotografia de nosso séc. XX - são pistas lacunares, heterogêneas, quase sempre suspeitas ou difíceis de serem interpretadas (JOMARON, 1992, p. 11, tradução minha). ${ }^{2}$

Pesquisar história e teatro, privilegiando práticas e representações, implica estabelecer uma relação importante, sobretudo ao interrogar os textos, as imagens e os sons como fontes (ler-ver-ouvir). O interesse concentra-se em compreender como é "historicamente produzido um sentido e diferenciadamente construída uma significação" (CHARTIER, 1988, p. 24). Como assinala Michel Foucault:

Racine não é sozinho o único e verdadeiro autor das tragédias racinianas, mas [...] estas nasceram no bojo do desenvolvimento de um conjunto estruturado de categorias mentais que era obra coletiva, o que me levou a encontrar como "autor" dessas tragédias, em última instância, a nobreza de toga, o grupo jansenista e, no interior deste, Racine como indivíduo particularmente importante (FOUCAULT, 2009, p. 290).

Partindo desses princípios reguladores, cabe lembrar que a recuperação das "práticas, complexas, múltiplas, diferenciadas” está em sintonia com a preocupação em entender como elas "constroem o mundo como representação" (CHARTIER, 1988, p. 24). Os textos não possuem um sentido oculto, intrínseco e único que caberia à crítica descobrir; "é necessário relembrar que todo o texto é o produto de uma leitura, uma construção do seu leitor" (CHARTIER, 1988, p. 61). Isso pode implicar numa "série de rasuras, emendas e amálgamas [...] em que a mente inconsciente $[. .$.$] transpõe incidentes de um registro do tempo para outro$ e materializa o pensamento em imagens" (SAMUEL, 1997, p. 45).

\footnotetext{
${ }^{2}$ Sobre a história do teatro francês no século XVIII, ver ROUGEMONT, 1988. Nessa obra, hoje referência para o estudo desse tema, vários aspectos da vida teatral são sistematizados e investigados pela primeira vez. A autora articula uma rigorosa relação entre a prática teatral - economia, sociologia, política - e a estética teatral, sem deixar de observar a condição de enunciação da representação propriamente dita.
} 
Nessa perspectiva, é possível perceber que os objetos teatrais podem ser utilizados como documentos na pesquisa do historiador, ajudando-o a compreender e a refletir sobre a realidade social de um determinado período. Uma história dos elementos constitutivos do espetáculo teatral não se apresenta como "outra história" em oposição e, portanto, divergente daquela que vem sendo repetida e que tradicionalmente elegeu o texto teatral como documento central de suas reflexões. Por outro lado, tampouco interessa banir o texto teatral desse espectro de discussão, mas, sim, entendê-lo como mais um elemento constitutivo com o qual se trama o fio da história. Como diz Fredric Jameson a propósito do filme Notícias da Antiguidade ideológica, de Alexander Kluge: ao refletirmos sobre a história, o que importa é a "miscelânea" ou a "montagem de sentimentos" (JAMESON, 2010, p. 69). Ademais, vale citar o que Roger Chartier escreve em relação à história e aos diferentes tipos de documentos:

A historicidade de um texto vem, ao mesmo tempo, das categorias de atribuição, de designação e de classificação dos discursos peculiares à época e ao lugar a que pertence, e dos seus próprios suportes de transmissão. Esta "materialidade do texto", que deve ser entendida como a inscrição de um texto na página impressa ou como modalidade de sua performance na representação teatral, introduz uma primeira descontinuidade, fundamental, na história dos textos: as operações e os atores necessários ao processo de publicação não são mais os mesmos antes e depois da invenção de Gutenberg, da industrialização da imprensa ou do começo da era do computador (CHARTIER, 2002, p. 11).

Desse modo, devemos nos perguntar quando o texto foi escrito, ou seja, em qual quadro histórico-cultural se insere. Martha Ribeiro adverte:

mesmo entendendo que um texto teatral possa (e deva) sugerir uma série de interpretações, isso não quer dizer que este texto possa permitir uma leitura qualquer, definida por desejos individuais exteriores ao próprio texto. [...] A qual tipo de leitor o texto se dirige? O que o texto pede ao leitor? Que tipo de cooperação o texto espera de seus leitores? Se todo texto se dirige a um leitor-modelo, deveríamos sempre nos perguntar no ato de leitura: qual tipo de leitor 
o texto quer que eu seja? Quais são os procedimentos e as estratégias utilizadas pelo texto para guiar este leitor fictício? (RIBEIRO, 2006, p. 29).

A atividade teatral dialoga com outros campos do fazer artístico, assim, é necessário incentivar uma história que dê conta das relações verificadas "dentro" e "fora" do fenômeno teatral. Nessa medida, tratase da compreensão do fato teatral como uma rede extensa e complexa de relações dinâmicas e plurais, que transitam entre a semiologia e a história, a sociologia e a antropologia, a técnica e a arte, o imaginário e a política, a cerimônia teatral e a cerimônia social.

Denis Guénoun (2003) destaca o caráter multifacetado do teatro em suas articulações e possibilidades, levando em consideração, para uma análise mais aprofundada, tanto o público como a arquitetura teatral, o autor e o ator. Da mesma forma, Roger Chartier (2002) evidencia outro aspecto extremamente importante do trabalho historiográfico: a "negociação" entre o teatro e o mundo social, ou seja, a "materialidade do texto", entendida como uma operação que inclui a produção do próprio texto (o discurso, a época), o lugar de produção e sua transmissão. José Ortega y Gasset lembra:

Um quadro [...] é uma "realidade imagem". [...] A coisa "quadro" pendurada na parede de nossa casa está constantemente transformando-se no rio Tejo, em Lisboa e em suas alturas. O quadro é imagem porque é permanente metamorfose - e metamorfose é o teatro, prodigiosa transfiguração. [...] O que vemos [...] no palco cênico, são imagens no sentido estrito que acabo de definir: um mundo imaginário; e todo teatro, por humilde que seja, é sempre um monte Tabor onde se cumprem transfigurações (ORTEGA Y GASSET, 1991, p. 36).

"O texto escrito tem uma presença visual assim como a imagem: a página impressa é visualizada como quadro tanto quanto a imagem" (MARIN, 1996, p. 122). Nesse sentido, o ato de ler um documento tem caráter diversificado, e as contribuições da semiótica nos auxiliam a perceber a existência simultânea de uma diversidade de linguagens constituídas em sistemas sociais e históricos de representação do mundo. Lembrando Jacques Le Goff: 
o documento não é inócuo. É antes de mais o resultado de uma montagem, consciente ou inconsciente, da história, da época, da sociedade que o produziram, mas também das épocas sucessivas durante as quais continuou a viver, talvez esquecido, durante as quais continuou a ser manipulado, ainda que pelo silêncio. $O$ documento é uma coisa que fica, que dura, e o testemunho, o ensinamento (para evocar a etimologia) que ele traz devem ser em primeiro lugar analisados desmistificando-lhe o seu significado aparente. O documento é monumento. Resulta do esforço das sociedades históricas para impor ao futuro - voluntária ou involuntariamente - determinada imagem de si próprias (LE GOFF, 1984a, p. 103).

Como se percebe, o espectro de ação do fato teatral, por si mesmo, transborda a representação de um texto teatral, e, consequentemente, sua multiplicidade é fulgurante. Uma dinâmica complexa que articula obras, programas, contextos, cenas, atores e performances. Arte e política se misturam e se contaminam, negociando continuamente a resistência e a gestão daquilo que é em relação ao que pode vir a ser, pondo em tensão o que está "dentro" e o que está "fora" do sistema instituído. Por meio das peças e dos espetáculos teatrais fundem-se diferentes expressões, imagens, metáforas, alegorias e outros elementos, que em conjunto compõem um cenário significativo de articulações de um modo de pensar e agir, de uma visão do mundo. Esse resultado reitera a noção de que as formas e produções culturais se criam e se recriam na trama das relações sociais, de produção e de reprodução da sociedade e de suas partes constitutivas. Afinal,

as histórias nunca ocorrem no vácuo, é claro. Nós nos engajamos no tempo e no espaço, dentro de uma sociedade em específico e de uma cultura maior. Os contextos de criação e recepção são tanto materiais, públicos e econômicos quanto culturais, pessoais e estéticos (HUTCHEON, 2011, p. 54). ${ }^{3}$

Os anos 1960, em especial, trariam novos e ricos rumos para o teatro, desde o Living Theater, seus rituais e hapennings, às teorias do polaco Jerzy Grotowski, autor de uma corrente mais despojada,

\footnotetext{
${ }^{3}$ Sobre o tema do engajamento, ver SCHWARZ, 1999.
} 
dando larga importância à expressão do corpo cênico, o chamado "teatro pobre", passando pelos angry young men da Inglaterra até Peter Brook e sua peculiar noção de espaço teatral e da nova relação palco/ público. Esses movimentos, observados em parte pelo mundo ocidental, correspondiam aos anseios de criadores, artistas e público jovem que não se reconheciam mais no teatro tradicional, questionando-o e buscando outras e mais desafiantes alternativas - transformando, amiúde, o teatro num laboratório, permeável às diferentes experiências e fusões com elementos cênicos de outras culturas.

Reclamava-se um novo teatro, exigindo-se uma relação distinta entre texto, público e criadores (atores e encenadores), algo que nos Estados Unidos era patente na ação de Elia Kazan, primeiro no Group Theatre (1931) e mais tarde no Lincoln Center (1961), com a criação do Lincoln Center Repertory Theatre, que tanto iria influenciar as jovens gerações - caso de Clifford Odets, Arthur Miller e Edward Albee. Por sinal, as bases programáticas do Lincoln Center Repertory Theatre estavam muito próximas das definidas, no mesmo ano, pelo Teatro Moderno de Lisboa (TML):

A criação do Teatro Moderno de Lisboa foi um dos momentos mais belos e exultantes da minha vida. Fui um dos seus fundadores mais entusiastas e empenhados. Estava tão saturado de fazer teatro comercial, cuja importância, aliás, reconheço, mas, tanto eu como os restantes companheiros desta autêntica aventura, queríamos voltar-nos agora para um teatro de grandes textos por nós escolhidos, moderno como o seu nome indicava, e que, por tal, nos desse um enorme gozo interpretar (CARVALHO apud LÍVIO, 2009, p. 178).

Lembro um fato ocorrido em julho de 1993. Naquele ano, Susan Sontag foi a Sarajevo - patrulhada pela ONU e sob os tiros dos sérvios - dirigir a peça Esperando Godot, de Samuel Beckett. O cenário era desolador: uma cidade sitiada e gélida, sob constantes ataques, sem iluminação no teatro (os ensaios e as apresentações foram realizados com luzes de velas), atores cansados, muitas vezes deprimidos e mal alimentados (SONTAG, 2005, p. 381-388). Nada disso foi obstáculo para o desejo de ter uma atividade cultural que combinasse realidade, arte e entretenimento. Ao contrário da fala inicial de Estragon, em Esperando 
Godot, que proclama "nada a fazer" (BECKETT, 2005, p. 17), aqueles homens buscaram vencer o medo e a depressão. "Ninguém na plateia fez o menor ruído. Os únicos ruídos eram os que vinham de fora do teatro: o estrépito de um veículo blindado das Nações Unidas, para transporte de pessoal, que passava pela rua e o estampido de um franco-atirador" (SONTAG, 2005, p. 411). Como afirmou certa vez Eric Hobsbawm, numa passagem bastante elucidativa:

nossas gerações [sofreram] do capitalismo uma lavagem cerebral para acreditar que a vida é o que o dinheiro pode comprar [...]. Há mesmo mais do que o desespero quanto a uma sociedade incapaz de dar a seus membros o que eles precisam, uma sociedade que força cada indivíduo ou cada grupo a cuidar de si próprio e não se importar com o resto. Já foi dito: "Dentro de cada trabalhador existe um ser humano tentando se libertar" (HOBSBAWM, 1987, p. 388).

\section{Teatro fora do eixo}

O processo cultural de produção social, em nossa perspectiva, é entendido como uma teia de significados e significantes. Se é verdade que a obra deve ser considerada em suas articulações internas, não é menos verdade que ao pensá-la isoladamente perdemos os sentidos que ela pode vir a ter, privando-nos da possibilidade de pensar se não estamos apenas repetindo interpretações consagradas. Como lembra Tânia Brandão:

O que se encontra na prateleira ao dispor do interessado são colchas de retalhos e fragmentos, recortes localizados. [...] A respeito de diversas regiões do Brasil, conhecemos muito pouco de sua história teatral; são mínimas as informações disponíveis sobre a história do circo, um capítulo decisivo para o conhecimento do teatro praticado no interior. A própria história de inúmeras companhias de atores, pequenas, efêmeras, permanece sem ser escrita. [...] Assim, a História do Teatro Brasileiro é sempre um desafio proposto às sucessivas gerações de estudiosos. Ou seja, a História do Teatro Brasileiro permanece por ser escrita, não foi escrita ainda (BRANDÃO, 2010, p. 338-339). 
É interessante assinalar que no início da década de 1980, Fernando Peixoto, no texto "Quando o povo assiste e faz teatro" - a propósito da peça Pensão liberdade, encenada pelo Grupo de Teatro Forja do Sindicato dos Metalúrgicos de São Bernardo -, salienta a importância do teatro popular como uma questão política, identificando a "estética popular e revolucionária" como "uma estética do oprimido, que exprime a ideologia da libertação" (PEIXOTO, 1981, p. 32-33). O tema do teatro popular entra novamente em cena, em plena ditadura militar no Brasil do pós1964. Experiências como a do Forja recolocavam, para pesquisadores e movimentos sociais, a questão de outra teatralidade, de outra estética, outra(s) história(s) e - por que não dizer? - de outra forma de intervenção nos movimentos populares.

Não é de hoje que se fala em "teatro popular" ou "teatro operário". A partir do fim do século XIX surgiram experiências de popularização do espetáculo teatral entre as classes trabalhadoras, mas também iniciativas dos próprios trabalhadores ligados às associações, clubes, sindicatos e/ou partidos, que visavam desenvolver um teatro de operários para operários. Propostas como o Freie Bühne (Cena Livre), de 1889, na Alemanha, e o Théatre du Peuple (Teatro do Povo), de 1885, na França, pretendiam ir além do mero barateamento do custo do ingresso. Homens de teatro, como Romain Rolland, em seus escritos, discutem desde o espaço cênico ao texto, procurando configurar objetivamente um projeto de teatro popular. Ao mesmo tempo, houve numerosas iniciativas vinculadas às associações e aos clubes operários em países distintos da Europa. A nova dramaturgia apontava como principal característica a celebração do trabalhador como tema e como intérprete, aliada à perspectiva do resgate dos temas sociais ${ }^{4}$ no teatro.

Voltando a atenção, por exemplo, ao teatro norte-americano da primeira metade do século XX, é possível recontar uma história a contrapelo. Iná Camargo Costa (2001) - num dos seus mais importantes trabalhos - recupera o movimento teatral dos trabalhadores norteamericanos, deixados ao esquecimento pela tradição que concebeu a história e a estética oficiais do teatro. Grupos teatrais como o $\operatorname{Artef}(1925)$, Workers Drama League (1926), Workers Laboratory Theatre (1930) e o Group Theatre (1931) não só mostravam suas ligações com anarquistas,

\footnotetext{
${ }^{4}$ Ver, entre outros, PARANHOS, 2007; COPFERMANN, 1971 e GARCIA, 2004.
} 
socialistas e comunistas - incluindo-se alguma aproximação entre intelectuais, artistas e militantes de esquerda -, mas também registravam as influências das propostas do teatro político de Piscator. ${ }^{5}$

Teatro político e teatro engajado são algumas denominações de um vivo debate que atravessou o final do século XIX e se consolidou no século XX. Para o crítico inglês Eric Bentley, o teatro político se refere tanto ao texto teatral como a quando, onde e como ele é representado. Aliás, ao saudar a presença do teatro engajado na década de 1960 nos Estados Unidos, ressalta que o fenômeno teatral por si só é subversivo:

onde quer que "duas ou três pessoas se reúnem", um golpe é desfechado contra as abstratas não-reuniões do público da $\mathrm{TV}$, bem como contra as reuniões digestivas de comerciantes exaustos na Broadway. [...] A subversão, a rebelião, a revolução no teatro não são uma mera questão de programa, e muito menos podem ser definidas em termos de um gênero particular de peças (BENTLEY, 1969, p. 178). ${ }^{6}$

Segundo Dias Gomes, em artigo de 1968, “o teatro é a única arte [...] que usa a criatura humana como meio de expressão. [...] Este caráter de ato político-social da representação teatral, ato que se realiza naquele momento e com a participação do público, não pode ser esquecido" (GOMES, 1968, p. 10). Em seu entendimento, coube ao teatro um papel de destaque na luta contra a ditadura implantada no Brasil em 1964. Afinal, desde Anchieta - "nosso primeiro dramaturgo" -, teatro e política estão umbilicalmente ligados à questão da função social da arte. A defesa do engajamento, portanto, parte do princípio de que os autores que falam sobre a realidade brasileira (sob diferentes óticas) são engajados. Isso significa dizer que o teatro é uma forma de conhecimento da sociedade. ${ }^{7}$

\footnotetext{
${ }^{5}$ Ver, entre outros, SAMUEL; MACCOLL; COSGROVE, 1985 e STOURAC; MCCEERY, 1986.

${ }^{6}$ Para Raymond Williams, o teatro político inclui Piscator e Brecht, sem falar que o teatro da crueldade de Artaud poderia, no limite, ser enquadrado sob essa mesma designação. Sobre o conceito de teatro político, ver WILLIAMS, 2002.

${ }^{7}$ Em um artigo de 1956, Jorge Andrade destacava: “'teatro brasileiro' não são textos estrangeiros bem encenados nem tampouco atores de primeira linha - é sobretudo texto, direção, interpretação, cenografia, música [...] determinados por nossa realidade. É necessário criar uma dramaturgia na qual os atores brasileiros sejam insuperáveis" (ANDRADE apud AZEVEDO, 2012, p. 14). É bom destacar que o dramaturgo -
} 
E mesmo quem se autoproclamava não engajado ou apolítico estava, na verdade, assumindo uma posição política. ${ }^{8}$

As experiências do teatro operário, do Arena, dos Centros Populares de Cultura (CPCs), do Oficina e do Opinião em busca do político e do popular carrearam um amplo movimento cultural que envolveu grupos, diretores, autores e elencos - que sofreram um violento revés com o golpe militar e, em particular, após ser decretado o AI-5, em 1968. A partir de então, para numerosos grupos, fazer um teatro popular significava assumir uma posição de rebeldia frente ao teatro comercial o "teatrão" - e ao regime político, presentes em algumas expressões que dizem dessa agitação, como "teatro independente" e "teatro alternativo". 9

No campo da cultura, em especial no teatro do Brasil pós-1964, é interessante destacar que, enquanto a maioria dos artistas estava profissionalmente vinculada à indústria cultural, outros buscavam provisoriamente o exílio, e alguns ainda tentavam resistir à modernização conservadora da sociedade, inclusive ao avanço da indústria cultural. Estes procuravam se articular com os chamados novos movimentos sociais, que aos poucos se organizavam mesmo com a repressão (sobretudo em alguns sindicatos e comunidades de bairro) e, muitas vezes, por meio de atividades associadas com setores de esquerda da Igreja Católica.

Em Santo André, por exemplo, foi fundado o Grupo de Teatro da Cidade (GTC), em 1968. Junto com outros grupos teatrais sediados na periferia paulistana (como Núcleo Expressão de Osasco, Teatro-Circo Alegria dos Pobres, Núcleo Independente, Teatro União e Olho Vivo, Grupo Ferramenta de Teatro, Grupo de Teatro Forja e outros), o GTC constitui-se como "teatro da militância", na expressão de Silvana Garcia. No entender da autora, os traços que mais "aproximariam esses grupos entre si e dariam a tônica do movimento dos independentes" seriam: "produzir coletivamente; atuar fora do âmbito profissional; levar o teatro para o público da periferia; produzir um teatro popular; estabelecer um compromisso de solidariedade com o espectador e sua realidade".

referência no pensamento sobre a formação do teatro moderno brasileiro e que não vinha da chamada tradição de militância - causou reações de desaprovação ou simplesmente de incômodo silêncio, tanto à direita quanto à esquerda.

${ }^{8}$ Ver GOMES, 1968, p. 13, 15, 17 e SCHWARZ, 1999.

9 O termo "independente" origina-se de países da Europa e da América Latina, onde a organização teatral se dá em moldes diferentes dos nacionais. Cf. DOSIO, 2003. 
Aspectos que não devem elidir a "sutileza das diferenças" entre os grupos, que garante a especificidade de cada um e marca as "divergências entre si” (GARCIA, 2004, p. 124).

Apesar da censura e da ditadura militar, nos anos 1960 e 1970, o teatro brasileiro continuava dando sinais de uma produção crescente e voltada, na maioria das vezes, para o campo político. Cabe realçar a atuação dos dramaturgos Jorge Andrade, Gianfrancesco Guarnieri, Augusto Boal, Dias Gomes, Ferreira Gullar, Oduvaldo Vianna Filho, Plínio Marcos, Carlos Queiroz Telles. Merecem também registro produções teatrais que traziam consigo a insatisfação com a ordem existente, como as do Teatro Universitário (TUCA/PUC-SP, TUSP/USP, TEMA/Teatro Mackenzie) e dos grupos Santa Edwiges (SP), Produções Artísticas Livres/PAL (SP), Grupo de Teatro Comute (SP), Grupo Teatro Debate do ABC (SP), Fora do Sério (SP), Teatro Jovem (RJ), Teatro Carioca de Arte (RJ), Dzi Croquettes (RJ), Asdrúbal Trouxe o Trombone (RJ), Teatro de Arena de Porto Alegre/TAPA (RS), Zabriskie (GO), Grita (CE), Imbuaça (SE), Sociedade Teatro dos Novos (BA), Teatro Livre da Bahia (BA), Oi Nóis Aqui Traveiz (RS). No início da década de 1980, novas companhias despontavam num Brasil ainda governado pelos militares, como o Tá na Rua (RJ) e o Galpão (MG). ${ }^{10}$

$\mathrm{O}$ teatro produzido no centro e na periferia urbana se associava aos movimentos sociais, o que evidenciava o aparecimento de novos públicos, novas temáticas, novas linguagens e a dinamização de canais de comunicação não convencionais. Sobretudo, o teatro da periferia se colocava como objeto na própria cena historiográfica. Desse modo, os grupos de teatro popular do pós-1964, que combatiam tanto a ditadura como a censura impostas, atuavam frequentemente nas franjas do circuito cultural. Fazer teatro engajado naquele período era buscar outros lugares de encenação, assim como outros olhares sobre os anos de chumbo. Vários desses grupos - a exemplo do Forja - uniam arte e rebeldia política. ${ }^{11}$

${ }^{10}$ Ver, entre outros, PACHECO, 1986; FERNANDES, 2000; PARANHOS, 2009 e VAZ, 2011.

${ }^{11}$ Vale lembrar histórias que ainda precisam ser contadas e que, por incrível que pareça, continuam ausentes de trabalhos recentes sobre o teatro brasileiro. Até porque, nesses casos, o alvo mira tão somente as grandes personalidades e/ou grupos mais consolidados na esfera do mercado. 
Benoît Denis salienta que o teatro é um "lugar" importante do engajamento. É exatamente aquele que propicia as formas mais diretas entre escritor e público: "através da representação teatral, as relações entre o autor e o público se estabelecem como num tempo real, num tipo de imediatidade de troca, um pouco ao modo pelo qual um orador galvaniza a sua audiência ou a engaja na causa que defende" (DENIS, 2002, p. 83).

A chamada "tomada de posição", seja ela qual for, é exatamente o que procura exprimir a noção de "engajamento" como figura que intervém criticamente na esfera pública, trazendo consigo não só a transgressão da ordem e a crítica ao existente, mas também a crítica de sua própria inserção no modo de produção capitalista e, portanto, a crítica da forma e do conteúdo de sua própria atividade. Engajamento "político" ou "legítimo", como lembra Eric Hobsbawm (1998, p. 146) noutro contexto, "pode servir para contrabalançar a tendência crescente de olhar para dentro", no caso, "o auto-isolamento da academia" (1998, p. 154), apontando, por assim dizer, para além dos circuitos tradicionais. ${ }^{13}$ A tomada de posição é o que aproxima trajetórias tão diferenciadas como as de Plínio Marcos, João das Neves, Ferreira Gullar e Dias Gomes, que se notabilizaram pela militância política e pela crítica social. ${ }^{14}$

No Brasil pós-1964, uma nova forma de pensar a arte era elaborada por grupos teatrais da periferia e por intelectuais e artistas que viraram as costas para os apelos da indústria cultural. Entre os chamados representantes do teatro de resistência, e, por que não dizer, engajado, Plínio Marcos é um dos nomes que se evidenciam. Da dramaturgia da tragédia à sua ligação com os grupos de teatro amador, sindicatos e/ ou movimentos sociais, destaca-se, nos anos do "milagre brasileiro", um fazer teatral distinto, que incluía temas como o subemprego, o desemprego, a marginalidade, a prostituição. ${ }^{15}$

\footnotetext{
${ }^{12}$ Sobre "teatro engajado" e "teatro de inspiração", ver CORRÊA, 1998, p. 147-156.

${ }^{13}$ Sobre as divergências, pós-Segunda Guerra, entre Sartre e Merleau-Ponty quanto à função política do intelectual na sociedade, ver CHAUI, 2006.

${ }^{14}$ Vale registrar que João das Neves, autor de $O$ último carro (1976), elaborou uma reflexão aguda sobre as contradições da sociedade brasileira, e também produziu uma estrutura cênica diferenciada no palco brasileiro.

${ }^{15} \mathrm{O}$ dramaturgo era figura constante no $\mathrm{ABC}$ paulista: participou de numerosos debates, seminários e palestras promovidos pelos sindicatos operários, assim como teve algumas de suas peças encenadas pelos grupos de teatro da região. Inúmeros são os exemplos de sua intervenção política na periferia de São Paulo. Em outubro de 1981, por exemplo,
} 
Os cenários apresentados não condizem em nada com os ideais do nacionalismo cego, do patriotismo orgulhoso bastante disseminado após 1964, ano do golpe. A maioria dos textos de Plínio Marcos encenados nos palcos, sobretudo brasileiros, ilustra a luta pela sobrevivência de sujeitos que, até então, eram esquecidos ou escondidos por certos segmentos por se distanciarem dos padrões de comportamento dominantes. Aparece representada a parcela da população à qual foi negado o mínimo de dignidade - impedindo qualquer idealismo ou esperança de mudança e que tem como única forma de protesto a violência, que não se volta apenas às classes dominantes, mas também aos seus pares.

Nas suas peças, avultam como temas a solidão e a decadência humanas, o círculo vicioso da tortura mútua e a absoluta falta de sentido das vidas degradadas, o beco sem saída da miséria, a violência, a superexploração do trabalho humano, trazendo a morte prematura com o horizonte permanente. Sobressaem sujeitos sociais distintos, marcados pelas tragédias individual e coletiva. Os personagens subvertem até um tipo de teatro engajado em voga nos anos de 1960 e 1970, pois em regra não veiculam uma mensagem otimista ou positiva quanto à possibilidade de se ter alguma esperança de mudança social. O que importa é subsistir, seja como for: sem solidariedade de classe, sem confiança no próximo. Seus personagens se debatem num mundo que não oferece vislumbre de redenção; estão envolvidos em situações mesquinhas e sórdidas, nas quais as lutas pela sobrevivência e pelo dinheiro não têm dignidade; frequentemente, enveredam para a marginalidade mais violenta a fim de atingir em seus objetivos.

Iná Camargo Costa, na orelha do livro Atuação crítica (CARVALHO, 2009), adverte que mesmo em "tempos de total colonização da sensibilidade e do imaginário pela indústria cultural; desafios práticos e teóricos [são] postos desde sempre aos que se dispõem a fazer teatro ou qualquer modalidade de arte consequente no Brasil". Felizmente, apesar dos tempos modernos e das dificuldades que eles geram, as experiências teatrais na contramão do pensamento dominante continuam em pauta e na ordem do dia com incrível tenacidade. Fazer teatro em meio às pressões comerciais é, sem dúvida, uma forma de provocação, de insubordinação ao mercado das "paradas de sucesso", da

foi apresentada no Sindicato de São Bernardo a peça Homens de papel, e em seguida ocorreu uma palestra do autor com os presentes. Cf. PARANHOS, 2011. 
qual ainda se valem o Teatro União e Olho Vivo (SP), o Engenho Teatral (SP), o Oi Nóis Aqui Traveiz (RS), o Tá na Rua (RJ) e o Galpão (MG). Sem falar, é claro, dos grupos estrangeiros.

A reescrita do teatro é um processo constante, tanto pela transformação do objeto - os discursos teatrais - como pelas mudanças dos códigos dos discursos críticos e dos deslocamentos de interesses ideológicos e estéticos dos sujeitos sociais que escrevem a história. Nisso tudo é relevante perceber diferentes categorias de discursos teatrais e, indo além da concepção teatral hegemônica, incorporar a preocupação que diz respeito à problemática das inclusões e exclusões, na seleção do corpo textual ou mesmo espacial. Tal opção significa eleger também outros textos e não apenas os fundadores, legitimados pela tradição cultural, e ainda tentar compreender como se deu o silenciamento dos textos não coincidentes ou não aceitáveis por essa tradição. Ir atrás do "não lugar", lembrando Michel de Certeau; introduzir o leitor, como ator, em outro(s) cenário(s).

Caminhando por trilhas diversas, distintos grupos de teatro, dramaturgos e diretores se notabilizaram pelo engajamento político aliado à crítica à sociedade capitalista. Como sismógrafos de seu tempo, lançaram ideias, perguntas e desafios no campo das artes que ecoam até hoje. Afinal, toda arte é política e deve levar em conta essa questão, até porque ela sempre é uma forma de participação. Vale lembrar uma passagem de Terry Eagleton, ao discutir o autor como produtor:

O artista verdadeiramente revolucionário, portanto, nunca se ocupa apenas com o objeto artístico, mas com os meios da sua produção. O “engajamento" não se limita à apresentação de opiniões políticas corretas pela arte; ele se revela no grau em que o artista reconstrói as formas artísticas à sua disposição, transformando autores, leitores e espectadores em colaboradores (EAGLETON, 2011, p. 112).

A despeito das dificuldades cotidianas, ainda podemos respirar outros ares. Por isso mesmo, e parafraseando Bertolt Brecht, apesar de tudo, mesmo quando somos derrotados, ainda temos a alternativa da lucidez. Dito de outra maneira: apesar do capitalismo selvagem - perdoeme a redundância, o que importa é continuar lutando para entender o que se passa. Farão ainda sentido estas palavras? Desce o pano. 


\section{Referências}

AZEVEDO, Elizabeth R.; MARTINS, Fernandinho; VIANA, Larissa de Oliveira Neves Fausto (Org.). Jorge Andrade 90 anos: (re)leituras. São Paulo: USP; Fapesp, 2012. v. 1: A voz de Jorge.

BECKETT, Samuel. Esperando Godot. São Paulo: Cosac Naify, 2005.

BENTLEY, Eric. O teatro engajado. Rio de Janeiro: Zahar, 1969.

BRANDÃO, Tânia. As lacunas e as séries: padrões de historiografia nas "Histórias do Teatro no Brasil". In: MOSTAÇO, Edelcio (Org.). Para uma história cultural do teatro. Florianópolis; Jaraguá do Sul: Design, 2010. p. 333-375.

CARVALHO, Sérgio de et al. Atuação crítica: entrevistas da Vintém e outras conversas. São Paulo: Expressão Popular, 2009.

CHARTIER, Roger. A história cultural. Lisboa: Difel, 1988.

CHARTIER, Roger. Do palco à página. Rio de Janeiro: Casa da Palavra, 2002.

CHAUI, Marilena. Intelectual engajado: uma figura em extinção?. In: NOVAES, Adauto (Org.). O silêncio dos intelectuais. São Paulo: Companhia das Letras, 2006. p. 19-43.

COPFERMANN, Émile. O teatro popular por quê?. Porto: Portucalense, 1971.

CORRÊA, José Celso Martinez. Primeiro ato. São Paulo: Editora 34, 1998.

COSTA, Iná Camargo. Panorama do Rio Vermelho: ensaios sobre o teatro americano. São Paulo: Nankin Editorial, 2001.

DENIS, Benoît. Literatura e engajamento: de Pascal a Sartre. Bauru: Edusc, 2002.

DOSIO, Celia. El Payró. Buenos Aires: Emecé, 2003.

EAGLETON, Terry. Marxismo e crítica literária. São Paulo: Editora Unesp, 2011.

FERNANDES, Sílvia. Grupos teatrais: anos 70. Campinas: Editora Unicamp, 2000. 
FOUCAULT, Michel. O que é um autor?. In: FOUCAULT, Michel. Estética: literatura e pintura, música e cinema. 2. ed. Rio de Janeiro: Forense Universitária, 2009. p. 264-298.

GARCIA, Silvana. Teatro da militância: a intenção do popular no engajamento político. 2. ed. São Paulo: Perspectiva, 2004.

GOMES, Dias. O engajamento é uma prática de liberdade. Revista Civilização Brasileira, Rio de Janeiro, n. 2, p. 7-17, 1968. Caderno Especial.

GUÉNOUN, Denis. A exibição das palavras: uma idéia (política do teatro). Rio de Janeiro: Teatro do Pequeno Gesto, 2003.

HOBSBAWM, Eric J. Mundos do trabalho. Rio de Janeiro: Paz e Terra, 1987.

HOBSBAWM, Eric J. Sobre história. São Paulo: Companhia das Letras, 1998.

HUTCHEON, Linda. Uma teoria da adaptação. Florianópolis: Ed. da UFSC, 2011.

JAMESON, Fredric. Filmar O capital?. Crítica Marxista, São Paulo, n. 30, p. 67-74, 2010.

JOMARON, Jacqueline de (Dir.). Le théâtre en France du moyen age à nos jours. Paris: Armand Colin, 1992.

LE GOFF, Jacques. Documento/monumento. In: ROMANO, Ruggiero (Org.). Enciclopédia Einaudi. Lisboa: Imprensa Nacional; Casa da Moeda, 1984a. v. 1. p. 95-106.

LE GOFF, Jacques. História. In: ROMANO, Ruggiero (Org.). Enciclopédia Einaudi. Lisboa: Imprensa Nacional/Casa da Moeda, 1984b. v. 1. p. 158-259.

LÍVIO, Tito. Teatro moderno de Lisboa (1961-1965): um marco na história do teatro português. Alfragide: Caminho, 2009.

MARIN, Louis. Ler um quadro: uma carta de Poussin em 1639. In: CHARTIER, Roger (Org.). Práticas da leitura. São Paulo: Estação Liberdade, 1996. p. 117-140.

ORTEGA Y GASSET, José. A idéia do teatro. Perspectiva: São Paulo, 1991. 
PACHECO, Tânia. Teatro alternativo em 70: a luz no final do túnel. In: MELLO, Maria Amélia (Org.). Vinte anos de resistência. Rio de Janeiro: Espaço e Tempo, 1986. p. 95-105.

PARANHOS, Kátia Rodrigues. El Grupo de Teatro Forja y Plínio Marcos: Dos perdidos em una noche sucia. Conjunto: Revista de Teatro Latinoamericano, La Habana, v. 1, n. 158-159, p. 21-35, 2011.

PARANHOS, Kátia Rodrigues. Textos, espaços e sujeitos sociais: outras linguagens na cena teatral brasileira. In: CARREIRA, André; LIMA, Evelyn Furquim Werneck (Org.). Estudos teatrais: GT História das Artes do Espetáculo/Abrace. Florianópolis: Editora da Udesc, 2009. p. 93-118.

PARANHOS, Kátia Rodrigues. Trabalho e cultura: elos da formação operária. In: INÁCIO, José Reginaldo (Org.). Sindicalismo no Brasil: os primeiros 100 anos?. Belo Horizonte: Crisálida, 2007. p. 95-115.

PEIXOTO, Fernando. Quando o povo assiste e faz teatro. In: GRUPO DE TEATRO FORJA DO SINDICATO DOS METALÚRGICOS DE SÃO BERNARDO DO CAMPO E DIADEMA. Pensão liberdade. São Paulo: Hucitec, 1981. p. 31-38.

RIBEIRO, Martha. Algumas considerações sobre a arte de "interpretar" um texto teatral. In: CARREIRA, André et al (Org.). Metodologias de pesquisa em artes cênicas. Rio de Janeiro: 7 Letras, 2006. p. 26-31.

ROUGEMONT, Martine de. La vie théâtrale en France au XVIIIe. siècle. Paris: Champion-Slatkine, 1988.

SAMUEL, Raphael. Teatros de memória. Projeto História, São Paulo, n. 14, p. 41-81, 1997.

SAMUEL, Raphael; MACCOLL, Ewan; COSGROVE, Stuart. Theatres of the Left 1880-1935: Workers' Theatre Movements in Britain and America. London: Routledge \& Kegan Paul, 1985.

SCHWARZ, Roberto. Nunca fomos tão engajados. In: Seqüências brasileiras: ensaios. São Paulo: Companhia das Letras, 1999. p. 172-177.

SONTAG, Susan. Questão de ênfase. São Paulo: Companhia das Letras, 2005.

STOURAC, Richard; MCCREERY, Kathleen. Theatre as a Weapon: Workers' Theatre in the Soviet Union, Germany and Britain, 1917-1934. London: Routledge \& Kegan Paul, 1986. 
VAZ, Toninho. Solar da fossa. Rio de Janeiro: Casa da Palavra, 2011. WILLIAMS, Raymond. El teatro como foro político. In: WILLIAMS, Raymond. La política del modernismo. Buenos Aires: Manantial, 2002. p. 109-124. 
